\title{
Corticostriatal Afferents Modulate Responsiveness to Psychostimulant Drugs and Drug-Associated Stimuli
}

\author{
KA Kerstetter ${ }^{1,5}$, AM Wunsch ${ }^{1,2,5}$, KG Nakata',2, E Donckels', JF Neumaier ${ }^{2,3,4}$ and Susan M Ferguson ${ }^{*, 1,2,3}$ \\ 'Center for Integrative Brain Research, Seattle Children's Research Institute, Seattle, WA, USA; ${ }^{2}$ Neuroscience Graduate Program, University of \\ Washington, Seattle, WA, USA; ${ }^{3}$ Department of Psychiatry and Behavioral Sciences, University of Washington, Seattle, WA, USA; ${ }^{4}$ Department of \\ Pharmacology, University of Washington, Seattle, WA, USA
}

\begin{abstract}
The medial prefrontal cortex (mPFC) and nucleus accumbens (NAc) are both integral components of the corticobasal ganglia-thalamic circuitry that regulates addiction-related behaviors. However, the role of afferent inputs from mPFC to NAc in these behaviors is unclear. To address this, we used a Cre-recombinase-dependent viral vector approach to express $\mathrm{G}_{\mathrm{i} / \mathrm{o}}$-coupled DREADDs (designer receptors exclusively activated by designer drugs) selectively in mPFC neurons projecting to the NAc and examined the consequences of attenuating activity of these neurons on the induction of amphetamine sensitization and on drug taking and drug seeking during cocaine selfadministration. Surprisingly, decreasing mPFC afferent activity to the NAc only transiently reduced locomotor sensitization and had no effect on drug taking during cocaine self-administration. However, inhibiting corticostriatal afferent activity during sensitization subsequently enhanced conditioned responding. In addition, this manipulation during drug self-administration resulted in slower rates of extinction and increased responding during drug prime-induced reinstatement - an effect that was normalized by inhibiting these corticostriatal afferents immediately before the drug prime. These results suggest that dampening cortical control over the NAc during drug exposure may lead to long-term changes in the ability of drugs and associated stimuli to drive behavior that has important implications for guiding treatments to prevent relapse.

Neuropsychopharmacology (20 I6) 4I, II28-I I37; doi:I0.I038/npp.20 I5.253; published online 23 September 2015
\end{abstract}

\section{INTRODUCTION}

Drug addiction is a debilitating neuropsychiatric disease characterized by a transition from controlled to uncontrollable drug taking and drug seeking and a high propensity to relapse, even after prolonged periods of drug abstinence. Chronic drug use produces adaptations within corticobasal ganglia-thalamic circuitry that are thought to underlie the behaviors that emerge during various stages of addiction (Kalivas and Volkow, 2011; Moussawi et al, 2011; Shiflett and Balleine, 2011). For example, morphological, electrophysiological, and neurochemical changes have been reported in both the striatum (ie, nucleus accumbens (NAc) and dorsal striatum), which is the central interface of this circuit, and the prefrontal cortex (PFC), which sends a strong glutamatergic input into the striatum (Berke and Hyman, 2000; Luscher and Malenka, 2011; Nestler, 2001; Russo et al, 2010; Schmidt and Pierce, 2010; Steketee and Kalivas, 2011). Although it has been postulated that a progressive reduction in PFC control over the striatum underlies many of the

*Correspondence: Dr SM Ferguson, Center for Integrative Brain Research, Seattle Children's Research Institute, 1900 Ninth Avenue, Seattle, WA 98109, USA, Tel: + I 206884 3279, Fax: + I 206884 1210,

E-mail: smfergus@uw.edu

${ }^{5}$ The first two authors contributed equally to this work.

Received 28 October 2014; revised 10 August 2015; accepted 13

August 2015; accepted article preview online 20 August 2015 behaviors that contribute to addiction (Goldstein and Volkow, 2011; Kalivas et al, 2005; Feil et al, 2010; Steketee and Kalivas, 2011), until recently there has been little direct evidence for this, in part because the high degree of neuronal interconnectivity between the cortex and other regions of the corticobasal ganglia-thalamic circuit has made these studies difficult to conduct. In addition, the striatum receives innervation from multiple glutamatergic sources (thalamus, amygdala, and hippocampus) along with the cortex (McGeorge and Faull, 1989; Wall et al, 2013), and hence studies using traditional approaches, such as lesions or pharmacological blockade, have been unable to isolate which projections are critical for modulating striatal function in addiction-related behaviors. Thus, elucidating how PFC afferents to striatum in particular regulate behaviors associated with psychostimulant use is crucial for our understanding of the neural substrates that mark a transition to addiction as well as those that underlie relapse.

To investigate this, we used a novel Cre-recombinase (Cre-)-dependent, intersectional viral vector approach to express $\mathrm{G}_{\mathrm{i} / \mathrm{o}}$-DREADDs (Designer Receptors Exclusively Activated by Designer Drugs) selectively in medial PFC (mPFC) afferents to NAc. DREADDs are only activated by clozapine- $\mathrm{N}$-oxide (CNO); thus, this strategy allows for the transient and targeted activation of $\mathrm{G}_{\mathrm{i} / \mathrm{o}}$-coupled signaling cascades in these neurons (Rogan and Roth, 2011). Activation of $\mathrm{G}_{\mathrm{i} / \mathrm{o}}$-DREADDs by CNO decreases neuronal 
activity primarily through a reduction in cAMP levels as well as activation of $G$ protein-coupled inwardly rectifying potassium (GIRK) channels, resulting in membrane hyperpolarization and inhibition of neuronal firing (Armbruster et al, 2007; Ferguson et al, 2011, see Sternson and Roth, 2014 for review). Accordingly, these tools were used to examine how transiently decreasing activity of $\mathrm{mPFC}$ neurons that project to NAc through recruitment of inhibitory $G$ protein-coupled signaling cascades affects the induction of psychomotor sensitization to amphetamine as well as the motivation to take drugs using a progressive ratio (PR) schedule of reinforcement in a cocaine self-administration paradigm and the motivation to seek drugs during drug prime-induced reinstatement. We hypothesized that decreasing activity of the cortical projections to NAc would block amphetamine sensitization as well as attenuate drug taking during cocaine self-administration and drug seeking during cocaine prime-induced reinstatement.

\section{MATERIALS AND METHODS}

\section{Experimental Strategy}

The overall experimental strategy was to use a combinatorial viral vector approach to express transgenes selectively in mPFC afferents to the NAc. This was achieved through injection of Cre-dependent adeno-associated virus (AAV) vectors into $\mathrm{mPFC}$ and a retrogradely transported canine adenovirus (CAV) expressing Cre into the NAc. Three separate experiments were then performed. In experiment 1 , cocaine-induced c-Fos expression was measured in the $\mathrm{mPFC}$ and the NAc following activation of $\mathrm{G}_{\mathrm{i} / \mathrm{o}}$-DREADDs in PFC to determine whether dampening PFC afferent input into the NAc was sufficient to decrease activity in NAc neurons. In separate experiments, the effect of dampening $\mathrm{mPFC}$ afferent input into the NAc was examined during the induction of amphetamine sensitization (experiment 2) and during cocaine self-administration (experiment 3) to determine whether corticostriatal projections modulate behaviors related to addiction. All experimental procedures were approved by the Seattle Children's Research Institute institutional animal care and use committee and were conducted in accordance with National Institutes of Health (NIH) guidelines.

\section{Viral Vectors}

Cre-dependent AAV (serotype 5) vectors driven by the human synapsin promotor and expressing $G_{i / o}-D R E A D D s$ (AAV-hSyn-DIO-hM ${ }_{4} \mathrm{Di}-\mathrm{mCherry} ; \mathrm{hM}_{4} \mathrm{Di}$ ) or the control GFP (green fluorescent protein; AAV-hSyn-DIO-EGFP; GFP) were constructed by Dr Bryan Roth and obtained from the University of North Carolina viral vector core (titer of $\sim 1 \times 10^{9}$ viral genomes/ $\mu \mathrm{l}$ ). CAV2-Cre (originally obtained from Dr Eric Kremer) was prepared in dog kidney (DK/E1-1) cells, purified by sucrose and $\mathrm{CsCl}$ gradient centrifugation steps, and resuspended in $1 \times$ Hanks' balanced saline solution at a titer of $\sim 2.5 \times 10^{9}$ viral genomes/ $\mu \mathrm{l}$ as described previously (Kremer et al, 2000).

\section{Experiment 1 (c-Fos)}

Male Long-Evans rats $(n=22$, Charles River) weighing $\sim 250-300 \mathrm{~g}$ were pair housed in a temperature- and humidity-controlled vivarium on a $12: 12 \mathrm{~h}$ light-dark cycle and maintained on ad libitum food and water access. For viral-mediated gene transfer, rats were anesthetized with $2-4 \%$ isoflourane (Webster Veterinary Supply) and given meloxicam $(0.2 \mathrm{mg} / \mathrm{kg}, \mathrm{s.c}$.) for pain management. Rats were monitored for at least 3 days following surgical procedures. Using standard stereotaxic procedures, 27-gauge stainless steel injectors were placed above the targeted brain regions. Coordinates from bregma $(\mathrm{mm})$ for $\mathrm{mPFC}$ were $\mathrm{A} / \mathrm{P} 3.2$, $\mathrm{M} / \mathrm{L} \pm 1.4$, and $\mathrm{D} / \mathrm{V}-3.5$ from skull surface, and for NAc were $\mathrm{A} / \mathrm{P} 1.7, \mathrm{M} / \mathrm{L} \pm 1.0$, and $\mathrm{DV}-6.5$. For assessment of cFos in the NAc, $2 \mu \mathrm{l}$ of GFP was injected in one hemisphere of the $\mathrm{mPFC}, 2 \mu \mathrm{l}$ of $\mathrm{hM}_{4} \mathrm{Di}$ was infused into the contralateral hemisphere of the mPFC, and $2 \mu \mathrm{l}$ of CAV-Cre was infused bilaterally into the NAc over a 10 -min period at a flow rate of $0.2 \mu \mathrm{l} / \mathrm{min}$. Thus, each rat $(n=7)$ had GFP in one hemisphere and $\mathrm{hM}_{4} \mathrm{Di}$ in the other hemisphere, allowing for a within-subject design for this experiment. For assessment of cFos in the mPFC and in the basolateral amygdala (BLA), rats received bilateral injections of CAV-Cre into NAc and bilateral injections of GFP $(n=7)$ or hM4Di $(n=7)$ in the $\mathrm{mPFC}$, allowing for a between-subject design. Accuracy of injection coordinates was confirmed by visualization of GFP or mCherry immunofluorescence in mPFC. At 20 days following viral infusions, rats were transported to a novel test environment and given an injection of $\mathrm{CNO}(3 \mathrm{mg} / \mathrm{kg}$, i.p.; obtained from the NIH as part of the Rapid Access to Investigative Drug Program funded by the NINDs) followed $20 \mathrm{~min}$ later by an injection of cocaine $(20 \mathrm{mg} / \mathrm{kg}$, i.p. $)$. After $2 \mathrm{~h}$, rats were killed and brains were processed for immunohistochemistry; c-Fos cells were counted in the $\mathrm{mPFC}$, the NAc, and the BLA. In addition, to assess whether the mPFC neurons projecting to the NAc also send collaterals to other brain regions within the corticostriatal circuit, GFP fluorescence was assessed in the NAc, the BLA, and the ventral hippocampus (VH).

\section{Experiment 2 (Sensitization)}

Male Sprague-Dawley rats $(n=52)$ underwent viralmediated gene transfer surgery as described for experiment 1 , except that the surgical coordinates and injection volumes were modified. Coordinates from bregma $(\mathrm{mm})$ for $\mathrm{mPFC}$ were $\mathrm{A} / \mathrm{P} 2.8, \mathrm{M} / \mathrm{L} \pm 0.8$, and $\mathrm{D} / \mathrm{V}-4.5$ from skull surface, and for NAc were A/P $1.8, \mathrm{M} / \mathrm{L} \pm 1.0$, and $\mathrm{DV}-7.5$, and rats received $1 \mu \mathrm{l}$ of each virus at each site.

The psychomotor-activating effects of amphetamine were measured using locomotor activity boxes (San Diego Instruments). Briefly, at least 14 days following viral infusions, rats received four injections of amphetamine $(2 \mathrm{mg} / \mathrm{kg}$, i.p., Sigma) or vehicle $(0.9 \%$ saline, i.p.) over a 7 -day treatment period (one injection occurring every other day). At $20 \mathrm{~min}$ before each drug treatment, all rats received an injection of CNO $(2 \mathrm{mg} / \mathrm{kg}$, i.p.). Following injections of amphetamine or vehicle, rats were placed into the locomotor activity boxes where behavior was recorded for $90 \mathrm{~min}$. After a 14-day withdrawal period, all rats underwent a challenge session. First, rats habituated to the locomotor chambers for 
$30 \mathrm{~min}$. Then they received an injection of saline followed by $30 \mathrm{~min}$ of behavioral testing to assess for a conditioned response. Finally, rats received a low-dose amphetamine challenge $(0.5 \mathrm{mg} / \mathrm{kg}$, i.p.) in the absence of $\mathrm{CNO}$ pretreatment followed by $90 \mathrm{~min}$ of behavioral testing to assess for the persistence of sensitization. The number of cage crossovers, defined as two consecutive beam breaks, was used as an index of locomotor activity. Stereotypy ratings were also assessed during testing using an adapted 9-point rating scale (Dougherty and Ellinwood, 1983). Rats were observed by an experimenter blind to the experimental conditions for $30 \mathrm{~s}$ every $5 \mathrm{~min}$ during the test sessions and were given a stereotypy rating during each observation ( 1 , asleep; 2 , inactive; 3 , normal in-place activity; 4 , normal, alert, active; 5, hyperactive; 6, slow patterned stereotyped behaviors; 7, fast patterned stereotyped behaviors; 8, restricted stereotyped behaviors; 9, dyskinetic reactive). There were four groups used in the psychomotor sensitization experiments: hM4Di rats injected with amphetamine $(n=13)$ or saline $(n=12)$ and GFP rats injected with amphetamine $(n=13)$ or saline $(n=12)$. Two rats were excluded from the analysis because virus expression was outside of mPFC.

\section{Experiment 3 (Self-Administration)}

Male Long-Evans rats $(n=35)$ underwent viral-mediated gene transfer surgery as described in experiment 1 , with rats receiving bilateral injections of either GFP $(n=7)$ or $\mathrm{hM}_{4} \mathrm{Di}$ $(n=15)$ into the mPFC and bilateral injections of CAV-Cre into the NAc. Following recovery, indwelling jugular catheters were implanted as previously described (Kerstetter et al, 2008). Briefly, catheters were inserted into the right jugular vein and connected to a back-mounted port. Catheters were flushed daily with Timentin antibiotic (20 mg/kg, i.v.; Butler Schein) and catheter patency was verified periodically with methohexital sodium infusions (10 mg/ml i.v.; Eli Lilly).

At least 14 days following viral infusions, rats were trained to self-administer cocaine $(0.75 \mathrm{mg} / \mathrm{kg} /$ infusion in $100 \mu \mathrm{l}$ of $0.9 \%$ sterile saline administered over $4 \mathrm{~s}$; obtained from the National Institute on Drug Abuse) during their light cycle on a fixed interval $20 \mathrm{~s}$ (FI:20) schedule of reinforcement. Each cocaine infusion was paired with a $5 \mathrm{~s}$ light and tone stimulus. Self-administration sessions lasted $2 \mathrm{~h}$ and took place 5 days per week in sound-attenuated operant conditioning chambers (Med Associates).

After rats had met self-administration criteria (minimum of 6 training sessions with 10 or more cocaine infusions earned for 3 consecutive sessions), they began PR sessions during which the response requirement to earn a cocaine infusion increased after each infusion earned. The response requirement progression followed that of Richardson and Roberts (1996) and was as follows: 1, 2, 4, 6, 9, 12, 15, 20, 25, $32,40,50,62,77,95,118,145,178,219,268,328,402,492$, 603. PR sessions were limited to $2 \mathrm{~h}$ because of the duration of CNO treatment (which was given during the testing phase). Once behavior had stabilized ( $\leq 2$-step change in the last response requirement completed in a session over 2 consecutive sessions), rats were administered vehicle (6\% DMSO in sterile water, i.p.) 20 min before PR testing for three sessions to obtain a baseline response. Rats were then administered $\mathrm{CNO}$ ( $3 \mathrm{mg} / \mathrm{kg}$, i.p.) $20 \mathrm{~min}$ before $\mathrm{PR}$ testing for three sessions. Following testing, rats underwent three additional PR sessions in the absence of any pretreatment to determine whether CNO treatment had any lasting effects on $\mathrm{PR}$ responding.

A subset of rats (GFP: $n=7 ; \mathrm{hM}_{4} \mathrm{Di}: n=5$ ) then underwent extinction of operant responding until criterion was met (a minimum of 7 sessions with at least 2 consecutive sessions of $\leq 25$ active lever responses). During the $2 \mathrm{~h}$ extinction sessions, levers were extended but responding did not have any programmed consequences (ie, no infusions or light/tone cue were given). Rats then received vehicle treatment immediately before being placed into the operant chamber to establish a baseline of responding. Rats then underwent two cocaine prime-induced reinstatement tests (10 mg/kg, i.p.) with either DMSO or $\mathrm{CNO}(3 \mathrm{mg} / \mathrm{kg}$, i.p.) given 20 min before the cocaine injections. Cocaine injections were given immediately before reinstatement testing, and levers were extended for these sessions but responding did not have any programmed consequences. These pretreatments were given in a counterbalanced manner and rats received additional extinction training sessions following the first reinstatement test (see Figure 4 for illustration of experimental design). In all, 13 rats were excluded from the experiments because 4 rats had injection sites outside of the $\mathrm{mPFC}, 7$ rats failed to acquire cocaine self-administration, and 2 rats were outliers from the behavioral data set $(>2$ SD away from the mean).

\section{Immunohistochemistry}

Rats were anesthetized with Beuthanasia-D (ScheringPlough) and perfused transcardially with $1 \times \mathrm{PBS}(\mathrm{pH} 7.4)$, followed by $4 \%$ paraformaldehyde (PFA). Brains were extracted, post-fixed in 4\% PFA overnight, and stored in $1 \times$ PBS. Floating sections $(40-60 \mu \mathrm{m})$ were washed in $0.5 \%$ Triton-X/PBS for $10 \mathrm{~min}$, blocked in $5 \%$ normal goat serum or $7.5 \%$ normal donkey serum (NS)- $0.25 \%$ Triton-X/PBS for $2 \mathrm{~h}$, and incubated in $2.5-5 \%$ NS- $0.25 \%$ Triton-X/PBS containing antibodies to GFP (1:400, Millipore), mCherry (1:400, Clontech), or c-Fos (1:400, Santa Cruz) with gentle agitation for $24-72 \mathrm{~h}$. Next, sections were rinsed 4 times in PBS and incubated in species-appropriate Alexa 488 (green), Alexa 568 (red), or Alexa 647 (far red)-conjugated secondary antibodies ( $1: 400$, Invitrogen) for $2 \mathrm{~h}$. Sections were washed 2 times in PBS, mounted on slides, and coverslipped with Vectashield mounting medium with DAPI (Vectorlabs). Z-stack images were captured with a Zeiss confocal microscope and compressed into a single plane before quantification. c-Fos+ cells in the mPFC, NAc, and BLA were counted and averaged across 3-4 sections for each rat using ImageJ software (NIH).

\section{Data Analysis}

All analyses consisted of planned (a priori) comparisons. Group differences in crossovers, stereotypy ratings, active and inactive lever presses, and number of earned infusions were tested using two-way analysis of variance (ANOVA) with repeated measures when applicable, followed by Bonferroni's post hoc tests. Differences in the number of $\mathrm{c}$-Fos+ cells were tested using a paired $t$-test for the NAc and 
a
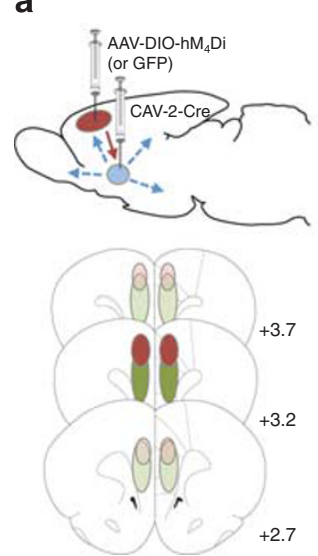

b
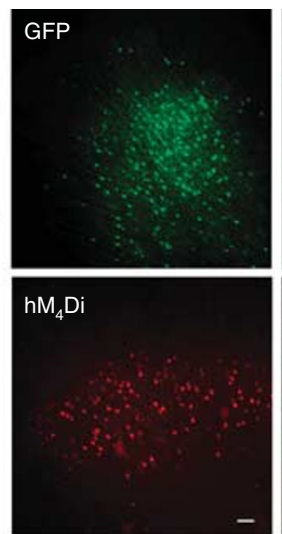

C
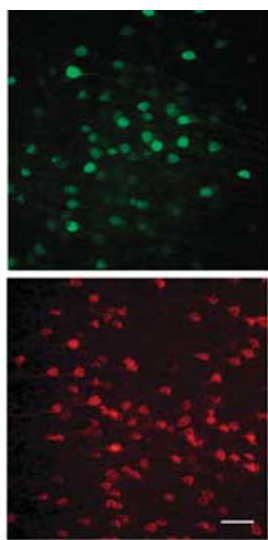
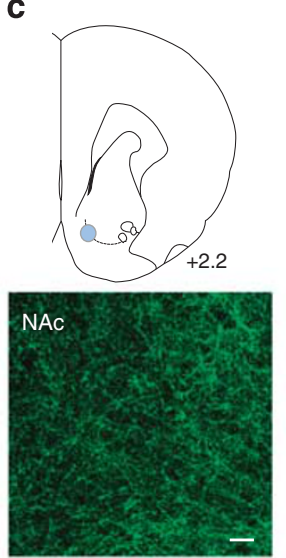

d
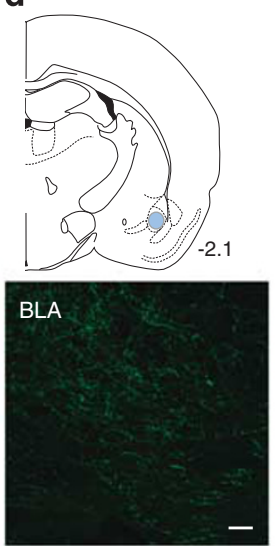

e
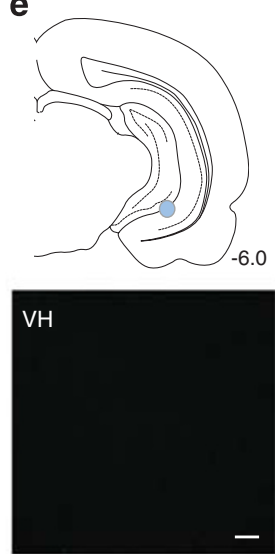

Figure I Viral vector expression. (a, top) Illustration of the intersectional viral vector approach: Cre-recombinase (Cre)-dependent AAV vectors ( $h M_{4}$ Di or GFP) were injected into the medial prefrontal cortex (mPFC) and the retrograde CAV-Cre virus was injected into the nucleus accumbens (NAc). (a, bottom) Viral spread is depicted in red for the self-administration experiments and in green for the sensitization experiments. Dark shading indicates areas of robust expression and light shading indicates areas with weaker expression. (b) Representative sections of GFP (top) and mCherry-tagged hM $\mathrm{M}_{4} \mathrm{Di}$ (bottom) immunofluorescence in PFC I4 days following viral infusions. (c-e) Representative sections of GFP immunofluorescence in NAc (c), basolateral amygdala (BLA) (d), and ventral hippocampus $(\mathrm{VH}) 8$ weeks following viral infusions. Scale bars, $40 \mu \mathrm{m}$.

unpaired $t$-tests for the $\mathrm{mPFC}$ and the BLA. For all comparisons, $\alpha \leq 0.05$. Data are graphed as mean \pm SEM.

\section{RESULTS}

The Intersectional Viral Vector Approach Produces Transgene Expression Primarily in mPFC Neurons Projecting to the NAc

A Cre-dependent intersectional vector approach was used to express $\mathrm{hM}_{4} \mathrm{Di}$ receptors in $\mathrm{mPFC}$ neurons projecting to the NAc in order to selectively and transiently decrease activity of these afferents (Figure 1a and b). Viral expression in the mPFC was largely confined to the cingulate and prelimbic regions (Figure 1). Although transgene expression was induced by retrograde infection of Cre from NAc neurons, it is possible that the DREADD-expressing $\mathrm{mPFC}$ neurons send collaterals to other regions. In order to confirm specificity of the intersectional approach, we examined fluorescence expression in $\mathrm{MPFC}$ terminals in the NAc, as well as the BLA and the $\mathrm{VH}$, the two output regions of the mPFC that also send glutamatergic inputs into the NAc. We observed a strong amount of fluorescence in the NAc (Figure 1c), with some fluorescence in the BLA (Figure 1d) and no fluorescence in the VH (Figure 1e), suggesting that DREADD receptor expression was occurring primarily in mPFC neurons that were projecting selectively to the NAc.

\section{Decreasing Activity of mPFC Afferents to NAc Reduces Cocaine-Induced c-Fos in Both PFC and NAc Neurons}

It is well established that activation of $\mathrm{hM}_{4} \mathrm{Di}$ receptors by CNO decreases neuronal activity primarily through a reduction in cAMP levels as well as activation of GIRK channels (Armbruster et al, 2007; Ferguson et al, 2011, see Sternson and Roth, 2014 for review). This effect has been observed in glutamatergic pyramidal neurons of the cortex, the population of neurons that expressed $\mathrm{hM}_{4} \mathrm{Di}$ receptors in the present set of experiments (Katzel et al, 2014; Kozorovitskiy et al, 2012; Robinson et al, 2014). Using cocaine-induced stimulation of the immediate early gene c-Fos as a marker of neuronal activity, we found that consistent with these studies, activation of $\mathrm{hM}_{4} \mathrm{Di}$ receptors in $\mathrm{mPFC}$ significantly decreased the number of cocaineevoked c-Fos + cells in mPFC by $\sim 30 \%$ compared with the GFP controls (Figure $2 \mathrm{a}$ and $\mathrm{b} ; t_{14}=2.68, P=0.02$ ). In order to extend these findings, we examined whether the manipulation in $\mathrm{mPFC}$ was sufficient to alter activity of the striatal neurons receiving $\mathrm{MPFC}$ input. Indeed, we found that activation of $\mathrm{hM}_{4} \mathrm{Di}$ receptors in mPFC significantly decreased the number of cocaine-evoked c-Fos+ cells in NAc by $\sim 32 \%$ compared with the GFP control hemisphere (Figure $2 \mathrm{c}$ and $\mathrm{d} ; t_{6}=0.56, P=0.01$ ), suggesting that decreasing activity of $\mathrm{mPFC}$ projections to NAc reduces the neuronal activity of its downstream targets. In contrast, $\mathrm{CNO}$-induced activation of $\mathrm{hM}_{4} \mathrm{Di}$ receptors in $\mathrm{mPFC}$ had no effect on cocaine-evoked c-Fos+ cells in the BLA (Figure $2 \mathrm{e}$ and $\mathrm{f} ; t_{13}=0.9, P=0.38$ ), suggesting that the manipulation was selective for altering activity in $\mathrm{MPFC}$ to NAc neurons.

\section{Decreasing Activity of mPFC Afferents to NAc Alters the Induction of Amphetamine Sensitization}

We used the intersectional DREADD viral vector approach to examine whether decreasing activity of mPFC afferents to NAc during amphetamine administration would be sufficient to block the induction of this progressive and persistent form of drug-induced behavioral plasticity. We found that CNO-induced activation of $\mathrm{hM}_{4} \mathrm{Di}$ receptors had no effect on locomotor activity following saline injections (Figure 3a; main effect of virus $\mathrm{F}_{1,22}=4.97, P=0.04$; main effect of session $\mathrm{F}_{3,66}=6.12, P=0.001$; no interaction between session and virus $\mathrm{F}_{3,66}=1.35, P=0.27$ ), suggesting a lack of effect of this manipulation on baseline activity. Although both locomotor and stereotyped responses to amphetamine increased over sessions in GFP and $\mathrm{hM}_{4}$ Di rats 
a
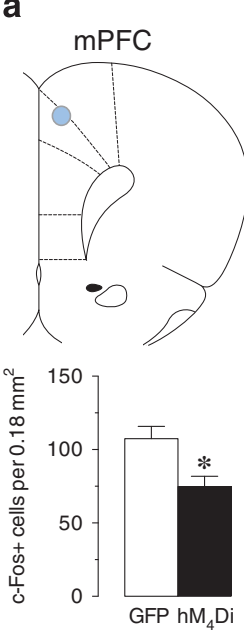

b

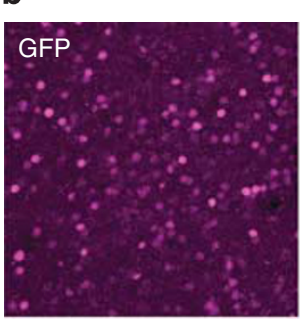

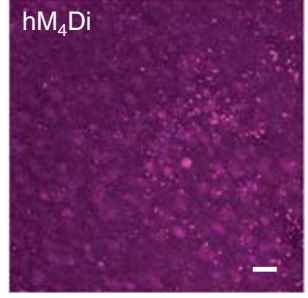

C

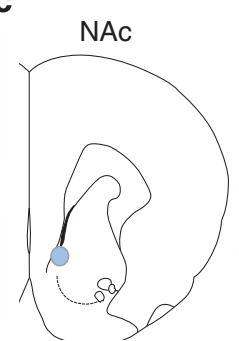

d
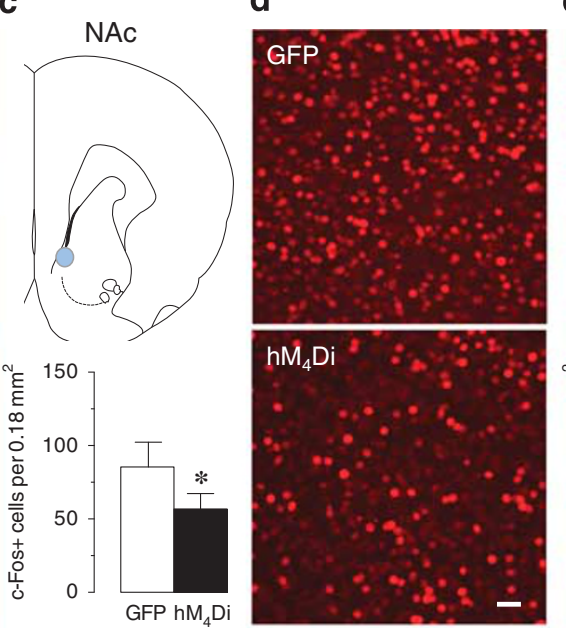

e
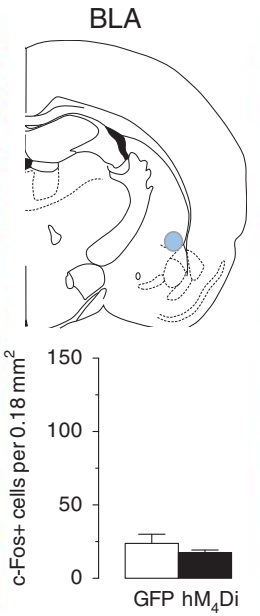

f
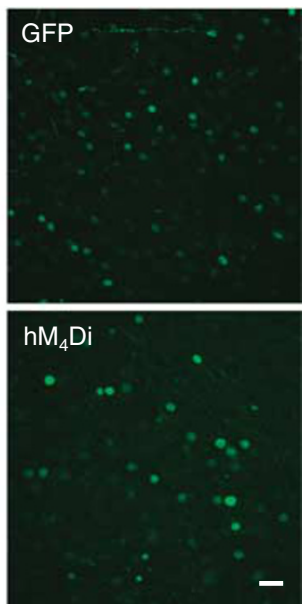

Figure 2 c-Fos expression. (a, c, and e) CNO-mediated activation of hM 4 Di-expressing mPFC neurons significantly reduces the number of cocaine-induced c-Fost cells in PFC ( $a, * P<0.05$ versus GFP group, $N=6-10)$ and NAc ( $c$, $* P<0.05$ versus GFP hemisphere, $N=7$ ) but not in $B L A$ (e, $P=0.38$ versus $G F P$ group, $N=7-8)$. (b, d, and f) Representative sections of Fos immunohistochemistry in mPFC (b), NAc (d), and BLA (f) are shown from GFP (top) and hM 4 Di sections (bottom). Scale bars, $40 \mu \mathrm{m}$.

(Figure 3a and b; locomotion: main effect of virus $\mathrm{F}_{1,24}=6.18, P=0.02$; main effect of session $\mathrm{F}_{3,72}=15.39$, $P<0.0001$; no interaction between session and virus $\mathrm{F}_{3,72}=1.15, \quad P=0.34$; stereotypy: main effect of session, $\mathrm{F}_{3,72}=99.3, \quad P<0.0001$; no effect of virus $\mathrm{F}_{1,24}=0.84$, $P=0.37$; no main effect of session and virus, $\mathrm{F}_{3,72}=0.84$, $P=0.48), \mathrm{hM}_{4} \mathrm{Di}$ rats had significantly reduced levels of locomotor activity during the last session compared with GFP controls $(P<0.05)$, suggesting that dampening activity of mPFC afferents to NAc attenuates the induction of locomotor sensitization.

Following 2 weeks of withdrawal, all rats underwent a challenge session. This was performed in the absence of $\mathrm{CNO}$ in order to assess whether decreasing activity of $\mathrm{mPFC}$ afferents to NAc during the induction of amphetamine sensitization has lasting effects. All rats underwent $30 \mathrm{~min}$ of habituation in the locomotor chambers, and there was no effect of the DREADD manipulation on locomotor activity during this phase (data not shown). Next, rats received an injection of saline to assess whether decreasing $\mathrm{mPFC}$ afferent activity during the induction phase altered conditioned responding to the injection procedure. Interestingly, $\mathrm{hM}_{4} \mathrm{Di}$ rats that had previously received amphetamine showed enhanced locomotor activity during this test compared with the $\mathrm{hM}_{4} \mathrm{Di}$ rats that had received saline, an effect not observed in the GFP groups (Figure 3c; main effect of drug pretreatment $\mathrm{F}_{1,46}=2.25, P=0.002$ ), suggesting that only $\mathrm{hM}_{4} \mathrm{Di}$ rats that received amphetamine treatment developed a conditioned response to the injection procedures associated with the drug. Finally, all rats received an injection of a low dose of amphetamine $(0.5 \mathrm{mg} / \mathrm{kg}$, i.p.). Both GFP and $\mathrm{hM}_{4} \mathrm{Di}$ rats that had received amphetamine during the induction phase showed similar levels of enhanced locomotor activity relative to the rats that had received saline during the induction phase (Figure 3d; main effect of drug pretreatment $\mathrm{F}_{1,46}=16.03, P=0.0002$; no main effect of virus $\mathrm{F}_{1,46}=0.74, P=0.39$; no interaction between drug pretreatment and virus $\mathrm{F}_{1,42}=0.06, P=0.81$ ), indicating that the level of sensitization during the challenge phase was similar across groups.

\section{Decreasing Activity of mPFC Afferents to NAc Has No Effect on Motivation for Taking Drugs}

To determine whether decreasing activity of mPFC afferents to NAc alters drug taking in a cocaine self-administration paradigm, rats were trained to self-administer cocaine first on a FI:20 schedule and then on a PR schedule of reinforcement until stable baselines were achieved (Figure 4). During the last three PR training sessions before testing, both GFP and $\mathrm{hM}_{4} \mathrm{Di}$ rats made significantly more active lever responses compared with inactive lever responses (Figure 4a; main effect of lever, $\mathrm{hM}_{4} \mathrm{Di}: \mathrm{F}_{1,28}=51.70$, $P<0.0001$; GFP: $\left.\mathrm{F}_{1,12}=50.73, P<0.0001\right)$ but there were no differences in lever responding across sessions (Figure $4 \mathrm{a}$; no main effect of session, $\mathrm{hM}_{4} \mathrm{Di}$ : $\mathrm{F}_{2,56}=1.57, P=0.38$; GFP: $\mathrm{F}_{2,24}=0.37, P=0.70$; no interaction between lever and session, $\mathrm{hM}_{4} \mathrm{Di}: \mathrm{F}_{2,56}=1.00, P=0.38 ; \mathrm{GFP}: \mathrm{F}_{2,24}=0.47$, $P=0.63)$. In addition, there were no differences in either active lever responses (Figure $4 \mathrm{a}$; no main effect of virus $\mathrm{F}_{1,20}=0.20, P=0.66$; no main effect of session $\mathrm{F}_{2,40}=0.03$, $P=0.97$; and no interaction between virus and session $\left.\mathrm{F}_{2,40}=1.42, \quad P=0.25\right)$ or number of earned infusions completed (Figure $4 \mathrm{~b}$; no main effect of virus $\mathrm{F}_{1,20}=0.14$, $P=0.71$; no main effect of session $\mathrm{F}_{2,40}=0.30, P=0.74$; and no interaction between virus and session $F_{2,40}=0.59$, $P=0.56$ ) between GFP and $\mathrm{hM}_{4}$ Di rats, suggesting that both groups had acquired the same stable levels of cocaine self-administration. Both groups then received vehicle pretreatment for three sessions, followed by $\mathrm{CNO}$ pretreatment for three sessions and three additional baseline sessions (data averaged across sessions). There were no differences between groups in active lever responses (Figure 4a; no main effect of virus $F_{1,20}=1.03, P=0.32$; no main effect of drug pretreatment $\mathrm{F}_{2,40}=0.53, \quad P=0.60$; and no interaction between virus and drug pretreatment $\mathrm{F}_{2,40}=1.90, P=0.16$ ) or number of earned infusions (Figure $4 \mathrm{~b}$; no main effect of 

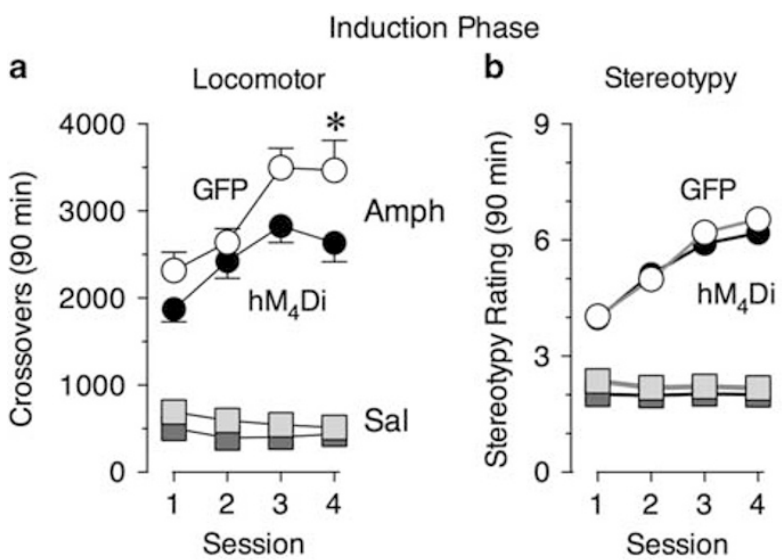

Challenge Phase: No CNO
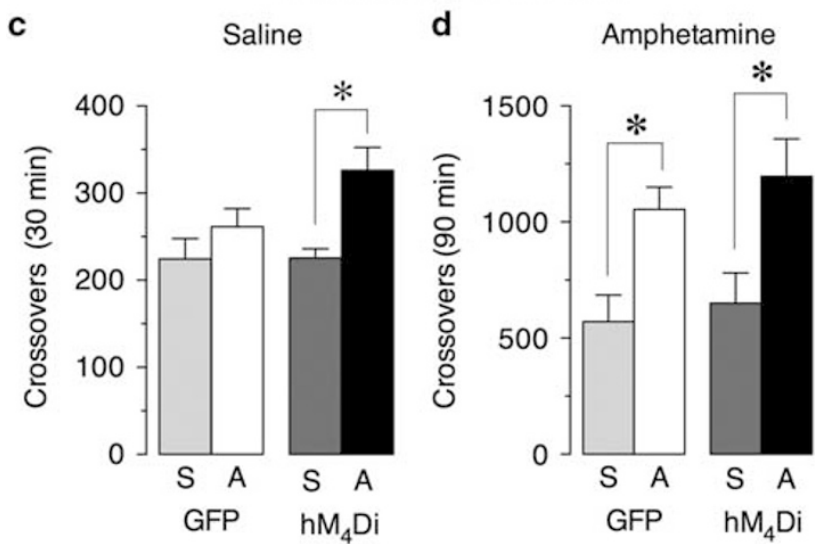

Figure 3 Amphetamine sensitization. Decreasing activity of mPFC afferents to NAc alters the development of amphetamine sensitization. $\mathrm{CNO}$-mediated activation of $\mathrm{hM}_{4} \mathrm{Di}$ in corticostriatal afferents significantly decreased locomotor sensitization to amphetamine as measured by crossovers ( $a, * P<0.05$ versus GFP group), but had no effect on stereotypy ratings (b). Decreasing activity of mPFC afferents to NAc during the induction phase of sensitization significantly increased conditioned responding as measured by crossovers during a saline challenge (c, $* P<0.05$ versus $\mathrm{hM}_{4} \mathrm{Di}$ group given saline during the induction phase), but had no effect on the persistence of locomotor sensitization as measured by crossovers during a low-dose amphetamine challenge $(0.5 \mathrm{mg} / \mathrm{kg}$, i.p.) in the absence of $\mathrm{CNO}$ pretreatment $(\mathrm{d}, * P<0.05$ versus respective control groups given saline during the induction phase). Data represent mean \pm SEM. Black symbols/shading $\left(h M_{4} \mathrm{Di}\right)$ and white symbols/shading (GFP) represent groups that received amphetamine treatment during the induction phase. Dark gray symbols/shading $\left(\mathrm{hM}_{4} \mathrm{Di}\right)$ and light gray symbols/shading (GFP) represent groups that received saline treatment during the induction phase. S: saline during the induction phase, $A$ : amphetamine during the induction phase. $N=||-\mid 7 /$ group.

virus $F_{1,20}=0.42, P=0.53$; no main effect of drug pretreatment $\mathrm{F}_{2,40}=1.07, P=0.35$; and no interaction between virus and drug pretreatment $\mathrm{F}_{2,40}=0.60, P=0.55$ ) across test sessions, suggesting that transiently decreasing corticostriatal afferent activity has no effect on drug taking.

\section{Decreasing Activity of mPFC Afferents to NAc Alters Motivation for Seeking Drugs}

To test whether decreasing activity of mPFC afferents to NAc alters drug seeking during drug-primed reinstatement, a subset of rats went through extinction training. Unexpectedly, $\mathrm{hM}_{4} \mathrm{Di}$ rats that had received CNO treatment during PR testing made significantly more active lever responses during the first 2 days of extinction training compared with the GFP controls (Figure 4c; main effect of virus $\mathrm{F}_{1,10}=12.90$, $P=0.005$; main effect of session $\mathrm{F}_{6,60}=50.07, P<0.0001$; and interaction between virus and session $\mathrm{F}_{6,60}=5.76$, $P<0.0001$ ), suggesting an impairment in their extinction learning. In addition, although both groups reached extinction criteria by 10 sessions, $\mathrm{hM}_{4} \mathrm{Di}$ rats made significantly more active lever responses following a priming injection of cocaine compared with the GFP controls (Figure 4d; main effect of virus $\mathrm{F}_{1,10}=2.67, P=0.03$; main effect of drug treatment $F_{2,20}=38.96, P<0.0001$; and interaction between virus and drug treatment $\mathrm{F}_{2,20}=9.19, P=0.002$ ), indicating a greater level of reinstatement. Interestingly, CNO treatment immediately before the cocaine prime significantly attenuated reinstatement in the $\mathrm{hM}_{4} \mathrm{Di}$ rats (Figure $4 \mathrm{~d}$; main effect of virus $\mathrm{F}_{1,10}=9.56, P=0.01$; main effect of pretreatment $\mathrm{F}_{2,20}=38.96, P<0.0001$; and interaction between virus and pretreatment $F_{2,20}=9.19, P=0.002$ ). These effects were not due to indiscriminate alterations in activity, as inactive lever responses did not differ between groups during extinction training (Figure 4c; no main effect of virus $\mathrm{F}_{1,10}=3.70, \quad P=0.08$; no interaction between virus and session $\left.\mathrm{F}_{6,60}=0.38, P=0.89\right)$ or during cocaine primeinduced reinstatement (no main effect of virus $F_{1,10}=0.29$, $P=0.60$; no main effect of drug pretreatment $\mathrm{F}_{1,10}=3.94$, $P=0.08$; and no interaction between virus and drug pretreatment $\mathrm{F}_{1,10}=1.26, P=0.29$ ), and $\mathrm{CNO}$ had no effect on cocaine prime-induced reinstatement in the GFP controls (Figure $4 \mathrm{~d} ; P=0.80)$.

\section{DISCUSSION}

We used a Cre-dependent intersectional viral vector approach to express $\mathrm{G}_{\mathrm{i} / \mathrm{o}}$-DREADDs in $\mathrm{mPFC}$ neurons that project to the NAc. Consistent with the known mechanism of $\mathrm{hM}_{4} \mathrm{Di}$ receptor activation, which is to reduce excitability of the cells expressing the $\mathrm{G}_{\mathrm{i} / \mathrm{o}}$-DREADDs (Armbruster et al, 2007; Ferguson et al, 2011, see Sternson and Roth, 2014 for review), we found that $\mathrm{CNO}$-induced receptor activation reduced cocaine-evoked c-Fos in the region of viral expression. In order to assess the specificity of this approach, we compared immunofluorescence in GFP-expressing rats in three terminal regions of the $\mathrm{mPFC}$ - the NAc, the BLA and the $\mathrm{VH}$. Although the densest amount of fluorescence was observed in the NAc, fluorescence was also apparent in the BLA, suggesting that the corticostriatal neurons that were expressing $G_{i / o}$-DREADDs may send axon collaterals to other regions. However, it is also possible that the signal in the BLA was simply because of axons passing through the region. In line with this idea, we found that activation of $\mathrm{hM}_{4} \mathrm{Di}$ receptors in $\mathrm{mPFC}$ attenuated cocaine-evoked c-Fos in NAc neurons but not in BLA neurons. Cocaine-induced activation of c-Fos in striatal cells is modulated by glutamate (Harlan and Garcia, 1998); thus, it is likely that the reduction in c-Fos that we observed following $\mathrm{hM}_{4} \mathrm{Di}$ receptor activation of corticostriatal neurons was because of a decrease in glutamatergic stimulation of the NAc neurons. In addition, these results indicate that the intersectional 


\begin{tabular}{|c|c|c|c|c|c|c|c|c|c|c|}
\hline \multirow{2}{*}{$\begin{array}{l}\text { Schedule } \\
\text { Treatment }\end{array}$} & \multirow{2}{*}{$\begin{array}{c}\mathrm{Fl}: 20 \\
--\end{array}$} & \multicolumn{4}{|c|}{ Progressive Ratio } & \multirow{2}{*}{$\begin{array}{c}\text { Extinction } \\
- \\
\end{array}$} & \multicolumn{4}{|c|}{ Reinstatement } \\
\hline & & - & V & C & - & & SAL & $v+\operatorname{coc}^{x}$ & Ext & $C+\operatorname{coc}^{x}$ \\
\hline Sessions & $7-10$ & $5-11$ & 3 & 3 & 3 & $7-10$ & 1 & 1 & 3 & 1 \\
\hline
\end{tabular}

\section{Progressive Ratio}

a

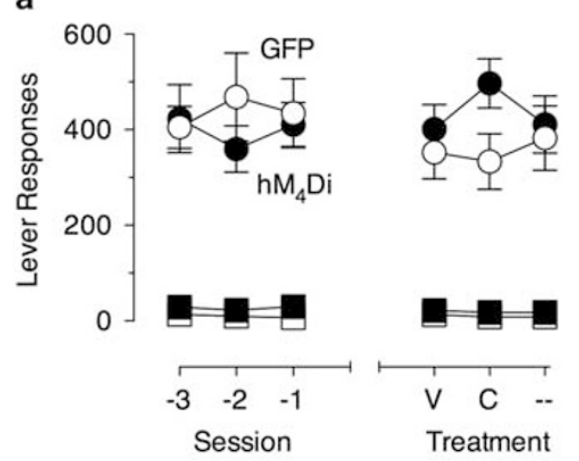

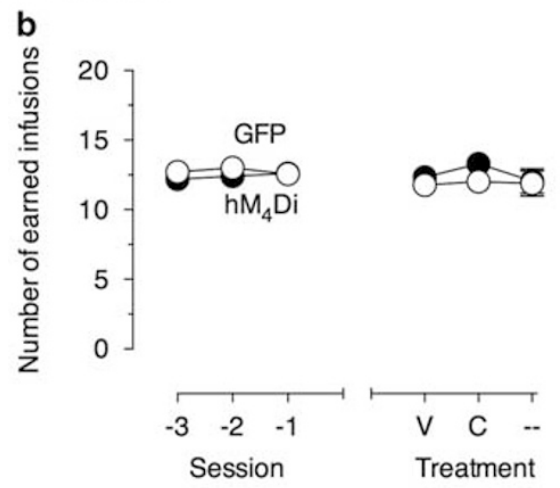

d

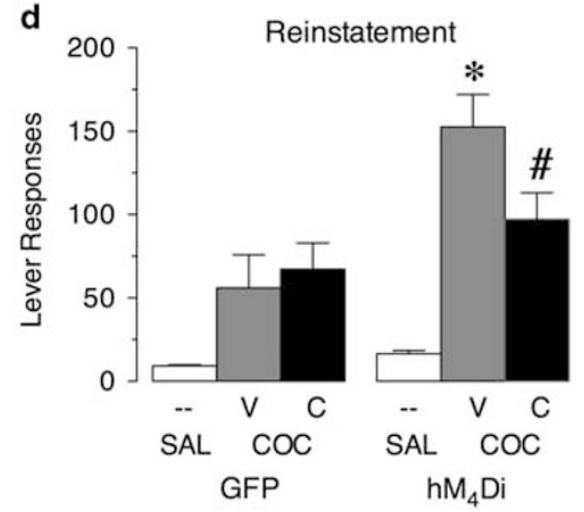

Figure 4 Cocaine self-administration. Decreasing activity in mPFC afferents to NAc modulates drug seeking. There were no differences between groups in active (circles) and inactive (squares) lever responses (a, left panel) and number of earned infusions (b, left panel) during baseline progressive ratio (PR) cocaine self-administration (last 3 sessions before testing). CNO-mediated activation of hM $4 \mathrm{Di}$ in corticostriatal afferents had no effect on lever responses (a, right panel) or number of earned infusions (b, right panel). Rats that had $h M_{4} D i$ activation during PR showed a significant increase in the number of active lever responses during the first 2 sessions of extinction training (c, $* P<0.05$ versus GFP group) as well as following a cocaine prime (d, *P $<0.05$ versus GFP group). CNO pretreatment before a cocaine prime significantly attenuated active lever responding only in the $h M_{4} D i$ group ( $d$, ${ }^{\#} P<0.05$ versus $V$-treated $h M_{4}$ Di group). Data represent mean \pm SEM. Black symbols in line graphs represent the $h M_{4}$ Di group and white symbols represent the GFP controls. ${ }^{\times}$Note that pretreatments ( $V$ or $C$ ) were counterbalanced across rats during reinstatement tests. SAL: saline injection; COC: cocaine injection; $V$ : vehicle pretreatment; C: CNO pretreatment. $N=5-7$ group.

approach was selective for modulating corticostriatal afferent activity.

Next, we examined the consequences of transiently decreasing activity in corticostriatal neurons during amphetamine administration on psychomotor sensitization. Given that previous work has demonstrated a role for the $\mathrm{mPFC}$ in regulating sensitization (Wolf, 1998; Vandershuren and Kalivas, 2000; Tzschentke and Schmidt, 2003; Kalivas, 2004; Steketee and Kalivas, 2011), and many of the sensitization-related neurobiological changes that occur in the NAc are glutamate dependent (Kalivas et al, 2005; Steketee and Kalivas, 2011), we hypothesized that selectively dampening mPFC activity to the NAc would decrease the induction of sensitization. Consistent with this hypothesis, decreasing activity of $\mathrm{mPFC}$ afferents to NAc during repeated amphetamine administration attenuated locomotor sensitization without altering stereotyped responses that are thought to be regulated by the dorsal striatum (Staton and Solomon, 1984). Unexpectedly, locomotor sensitization appeared equivalent between groups during the challenge phase. There are several possible explanations that could account for these results. First, the observed effects during the induction phase could be due to a decrease in the expression of sensitization; this is unlikely to be the case as differences in the level of sensitization were only observed during the last treatment session. Second, it is possible that our manipulation initially decreased the induction of sensitization, but the underlying neurobiological changes that occur in corticostriatal circuits during withdrawal permitted sensitization to develop normally over the long term. Third, it may be that decreasing mPFC afferent activity to the NAc did, in fact, permanently disrupt the induction of sensitization, and the response during the amphetamine challenge was a reflection of other processes that were altered 
during the DREADD manipulation, such as an increase in conditioned responding. In support of this last idea, we found that attenuating activity in cortical projections to NAc during the induction of amphetamine sensitization resulted in the development of a conditioned response to the injection procedure as measured during the saline challenge-an effect not seen in the controls.

Nonetheless, these results suggest that direct modulation of NAc activity by the mPFC is unlikely to be a critical node in the modulation of behavioral sensitization. Instead, it is likely that the mPFC exerts its effects on NAc indirectly through regulation of other NAc inputs, such as VTA, to modulate sensitization, and other sources of glutamate (ie, amygdala, hippocampus, or thalamus) must be responsible for direct modulation of the NAc. Consistent with this idea, it was recently demonstrated that optical inhibition of $\mathrm{VH}$ inputs into the NAc shell was sufficient to reduce the development of locomotor sensitization to cocaine (Britt et al, 2012). In addition, decreasing activity of the BLA via $G_{i / o}-D R E A D D s$ not only attenuated the development of cocaine sensitization but also blocked cocaine-induced increases in the frequency of miniature excitatory postsynaptic currents in NAc neurons, suggesting that NAc activity is directly modulated by amygdala afferents (MacAskill et al, 2014). However, it should be noted that in the present set of experiments DREADD receptors were primarily expressed in the cingulate and prelimbic regions of the $\mathrm{mPFC}$; thus, we cannot rule out that targeting a larger region of the PFC and/or more medial aspects could lead to a different behavioral outcome. This is unlikely to be the case, however, as previous work has demonstrated that lesions of or pharmacological manipulations to this region of $\mathrm{mPFC}$ are sufficient to modulate sensitization (Tzschentke and Schmidt, 2003).

Finally, we examined the consequences of transiently decreasing activity in corticostriatal neurons on drug taking during cocaine self-administration and on drug prime-induced reinstatement following extinction. Although this manipulation had no effect on on-going drug use during self-administration, inhibiting mPFC afferent activity to the NAc immediately before drug prime decreased reinstatement. This finding is consistent with recent studies that found that optogenetic inhibition of prelimbic PFC fibers in the NAc core also blocks both cocaine prime-induced reinstatement and cocaine-plus-cue-induced reinstatement (Stefanik et al, 2013, 2015). In addition, it is consistent with recent work demonstrating that reversing silent synapse remodeling (that occurred during withdrawal from cocaine self-administration) in the NAc core by optical stimulation of PFC inputs inhibited cue-induced cocaine seeking (Ma et al, 2014). Finally, these results are in line with the idea that heightened PFC activation underlies the enhanced responsiveness seen to drugs and drug-related cues during relapse (Feil et al, 2010; Goldstein and Volkow, 2011).

Although decreasing cortical activity to NAc neurons did not alter drug-taking behavior during cocaine self-administration, it did have a large impact on subsequent responsiveness to the environmental stimuli associated with drug administration and to the drug itself. Specifically, decreasing activity in these neurons during cocaine self-administration led to a slower rate of extinction and an increase in active lever pressing during drug prime-induced reinstatement compared with controls. Together with the enhanced conditioned response seen following amphetamine sensitization, these results suggest that cortical inputs into NAc may be modulating the strength of associations between drugs and the circumstances surrounding drug administration (ie, 'set and setting') and are consistent with imaging studies in human addicts as well as in preclinical animal models that have found that, relative to controls, extensive psychostimulant use results in a hypoactive PFC at baseline but heightened PFC activation to both the drug and drug-related cues (Goldstein and Volkow, 2011).

Nonetheless, it is perhaps counterintuitive that dampening $\mathrm{mPFC}$ afferent activity to NAc during initial drug use would subsequently lead to the development of a conditioned response, as well as the delayed extinction and enhanced responding during drug prime-induced reinstatement (all of which occurred in the absence of DREADD receptor activation). However, although much work has focused on the brain regions and circuits that regulate how drug-associated stimuli drive reinstatement of cocaineseeking behavior (Everitt and Robbins, 2005; LaLumiere et al, 2012; Marchant et al, 2014), surprisingly little is known about the neural mechanisms that underlie how drugs initially change the incentive value of the stimuli that become associated with drug use. Our results indicate that increasing $\mathrm{G}_{\mathrm{i} / \mathrm{o}}$ signaling in corticostriatal neurons could help drive the strength of these associative processes. In addition to reducing cAMP activity and activating GIRK channels (Sternson and Roth, 2014), induction of $\mathrm{G}_{\mathrm{i} / \mathrm{o}}$ cascades produces a slow and sustained increase in ERK/MAPK (extracellular signal-regulated kinase) signaling through a $\beta$-arrestin-mediated pathway (Reiter and Lefkowitz, 2006; Wettschureck and Offermanns, 2005). ERK/MAPK signaling cascades are important modulators of long-term alterations in neuronal plasticity and memory formation (Giovannini, 2006; Sweatt, 2004), and it is noteworthy that the changes in responsiveness to the stimuli associated with drug use took a period of time to develop, as they were not evident during the induction of sensitization (that appeared blunted) or in the three baseline self-administration sessions that followed CNO treatment. Thus, $\beta$-arrestin-mediated recruitment of ERK/MAPK cascades during drug use is one possible mechanism that could facilitate the strengthening of associations between the drug and the stimuli. Nonetheless, the striatum receives innervation from multiple glutamatergic sources (thalamus, amygdala, and hippocampus) along with the cortex (McGeorge and Faull, 1989; Wall et al, 2013), and it is not yet known whether these inputs work in concert or in opposition to regulate NAc neurons and subsequent behavioral output. Thus, it is also possible that dampening mPFC activity allowed for the information that is carried from these other inputs to have a larger impact on NAc neuron function, thereby facilitating the development of associations between the drug and the 'set and setting' surrounding drug use.

In summary, this work helps to elucidate how mPFC afferents to NAc, in particular, regulate addiction-related behaviors and govern the processes that contribute to relapse. Our results suggest that rather than modulating the maintenance of ongoing behaviors as previously thought, these afferent connections from mPFC to NAc may instead be key for shaping the associations between drugs and the 
stimuli surrounding drug use, as well as in reinstatement of drug-seeking behaviors. Given that relapse to drugs following exposure to drug-associated stimuli is one of the most insidious facets of addiction, particularly because it is such a persistent phenomenon (Frawley and Smith, 1992; Jones et al, 2003), this work has important clinical implications as it suggests that the mPFC to NAc input would be a promising target for therapeutic intervention.

\section{FUNDING AND DISCLOSURE}

The authors declare no conflict of interest.

\section{ACKNOWLEDGMENTS}

This work was supported by US National Institutes of Health grants F32 DA036326 (to KAK), R01 DA030807 (to JFN), and R01 DA036582 (to SMF). We thank Robin Stewart for assisting in the self-administration experiments and Dr Michele Kelly for packaging the CAV-Cre.

\section{AUTHOR CONTRIBUTIONS}

KAK, AMW, KGN, and ED performed the behavioral and immunohistochemical experiments. JFN provided the CAV-Cre. KAK, AMW, and SMF designed the overall study and wrote the manuscript. All authors contributed to data interpretation and manuscript editing.

\section{REFERENCES}

Armbruster BN, Li X, Pausch MH, Herlitze S, Roth BL (2007). Evolving the lock to fit the key to create a family of $G$ proteincoupled receptors potently activated by an inert ligand. Proc Natl Acad Sci USA 104: 5163-5168.

Berke JD, Hyman SE (2000). Addiction, dopamine, and the molecular mechanisms of memory. Neuron 25: 515-532.

Britt JP, Benaliouad F, McDevitt RA, Stuber GD, Wise RA, Bonci A (2012). Synaptic and behavioral profile of multiple glutamtergic inputs to the nucleus accumbens. Neuron 76: 790-803.

Dougherty GG, Ellinwood EH (1983). Influence of gammabutyrolactone on behavior due to dopaminergic drugs. Physiol Behav 30: 607-612.

Everitt BJ, Robbins TW (2005). Neural systems of reinforcement for drug addiction: from actions to habits to compulsions. Nat Neurosci 8: 1481-1489.

Feil J, Sheppard D, Fitzgerald PB, Yucel M, Lubman DI, Bradshaw JL (2010). Addiction, compulsive drug seeking, and the role of frontostriatal mechanisms in regulating inhibitory control. Neurosci Biobehav Rev 35: 248-275.

Ferguson SM, Eskenazi D, Ishikawa M, Wanat MJ, Phillips PE, Dong $\mathrm{Y}$ et al (2011). Transient neuronal inhibition reveals opposing roles of indirect and direct pathways in sensitization. Nat Neurosci 14: 22-24.

Frawley PJ, Smith JW (1992). One-year follow-up after multimodal inpatient treatment for cocaine and methamphetamine dependencies. J Subst Abuse Treat 9: 271-286.

Giovannini MG (2006). The role of the extracellular signal-regulated kinase pathway in memory encoding. Rev Neurosci 17: 619-634.

Goldstein RZ, Volkow ND (2011). Dysfunction of the prefrontal cortex in addiction: neuroimaging findings and clinical implications. Nat Rev Neurosci 12: 652-669.

Harlan RE, Garcia MM (1998). Drugs of abuse and immediate early genes in the forebrain. Mol Neurobiol 16: 221-267.
Jones EM, Knutson D, Haines D (2003). Common problems in patients recovering from chemical dependency. Am Fam Physician 68: 1971-1978.

Kalivas PW (2004). Recent understanding in the mechanisms of addiction. Curr Psychiatry Rep 6: 347-351.

Kalivas PW, Volkow N, Seamans J (2005). Unmanageable motivation in addiction: a pathology in prefrontal-accumbens glutamate transmission. Neuron 45: 647-650.

Kalivas PW, Volkow ND (2011). New medications for drug addiction hiding in glutamatergic neuroplasticity. Mol Psychiatry 16: 974-986.

Katzel D, Nicholson E, Schorge S, Walker MC, Kullmann DM (2014). Chemical-genetic attenuation of focal neocortical seizures. Nat Commun 5: 3847.

Kerstetter KA, Aguilar VR, Parrish AB, Kippin TE (2008). Protracted time-dependent increases in cocaine-seeking behavior during cocaine withdrawal in female relative to male rats. Psychopharmacology 198: 63-75.

Kozorovitskiy Y, Saunders A, Johnson CA, Lowell BB, Sabatini BL (2012). Recurrent network activity drives striatal synaptogenesis. Nature 485: 646-650.

Kremer EJ, Boutin S, Chillon M, Danos O (2000). Canine adenovirus vectors: an alternative for adenovirus-mediated gene transfer. J Virol 74: 505-512.

LaLumiere RT, Smith KC, Kalivas PW (2012). Neural circuit competition in cocaine-seeking: roles of the infralimbic cortex and nucleus accumbens shell. Eur J Neurosci 35: 614-622.

Luscher C, Malenka RC (2011). Drug-evoked synaptic plasticity in addiction: from molecular changes to circuit remodeling. Neuron 69: 650-653.

Ma YY, Lee BR, Wang X, Guo C, Liu L, Cui R et al (2014). Bidirectional modulation of incubation of cocaine craving by silent synapse-based remodeling of prefrontal cortex to accumbens projections. Neuron 83: 1453-1467.

MacAskill AF, Cassel JM, Carter AG (2014). Cocaine exposure reorganizes cell type- and input-specific connectivity in the nucleus accumbens. Nat Neurosci 17: 1198-1207.

Marchant NJ, Kaganovsky K, Shaham Y, Bossert JM (2014). Role of corticostriatal circuits in context-induced reinstatement of drug seeking. Brain Res. Available at http://www.sciencedirect. com/science/article/pii/S0006899314011913 (e-pub ahead of print 6 September 2014; doi:10.1016/j.brainres.2014.09.004).

McGeorge AJ, Faull RL (1989). The organization of the projection from the cerebral cortex to the striatum in the rat. Neuroscience 29: 503-537.

Moussawi K, Zhou W, Shen H, Reichel CM, See RE, Carr DB et al (2011). Reversing cocaine-induced synaptic potentiation provides enduring protection from relapse. Proc Natl Acad Sci USA 108: 385-390.

Nestler EJ (2001). Molecular basis of long-term plasticity underlying addiction. Nat Rev Neurosci 2: 119-128.

Reiter E, Lefkowitz RJ (2006). GRKs and beta-arrestings: roles in receptor silencing, trafficking and signaling. Trends Endocrinol Metab 17: 159-165.

Richardson NR, Roberts DC (1996). Progressive ratio schedules in drug self-administration studies in rats: a method to evaluate reinforcing efficacy. J Neurosci Methods 66: 1-11.

Robinson S, Todd TP, Pasternak AR, Luikart BW, Skelton PD, Urban DJ et al (2014). Chemogenetic silencing of neurons in retrosplenial cortex disrupts sensory preconditioning. J Neurosci 34: 10982-10988.

Rogan SC, Roth BL (2011). Remote control of neuronal signaling. Pharmacol Rev 63: 291-315.

Russo SC, Dietz DM, Dumitriu D, Malenka RC, Nestler EJ (2010). The addicted synapse: mechanisms of synaptic and structural plasticity in nucleus accumbens. Trends Neurosci 33: 267-276.

Schmidt HD, Pierce RC (2010). Cocaine-induced neuroadaptations in glutamate transmission: potential therapeutic targets for craving and addiction. Ann NY Acad Sci 1187: 35-75. 
Shiflett MW, Balleine BW (2011). Molecular substrates of action control in cortico-striatal circuits. Prog Neurobiol 95: 1-13.

Staton DM, Solomon PR (1984). Microinjections of d-amphetamine into the nucleus accumbens and caudate-putamen differentially affect stereotypy and locomotion in the rat. Physiol Psychol 12: 159-162.

Stefanik MT, Kupchik YM, Kalivas PW (2015). Optogenetic inhibition of cortical afferents in the nucleus accumbens simultaneously prevents cue-induced transient synaptic potentiation and cocaine-seeking behavior. Brain Struct Funct (e-pub ahead of print 7 February 2015; doi:10.1007/s00429-015-0997-8).

Stefanik MT, Moussawi K, Kupchik YM, Smith KC, Miller RL, Huff ML et al (2013). Optogenetic inhibition of cocaine seeking in rats. Addict Biol 18: 50-53.

Stekette JD, Kalivas PW (2011). Drug wanting: behavioral sensitization and relapse to drug-seeking behavior. Pharmacol Rev 63: 348-365.
Sternson SM, Roth BL (2014). Chemogenetic tools to interrogate brain functions. Annu Rev Neurosci 37: 387-407.

Sweatt JD (2004). Mitogen-activated protein kinases in synaptic plasticity and memory. Curr Opin Neurobiol 14: 3111-3117.

Tzschentke TM, Schmidt WJ (2003). Glutamatergic mechanisms in addiction. Mol Psychiatry 8: 373-382.

Vandershuren LJ, Kalivas PW (2000). Alterations in dopaminergic and glutamatergic transmission in the induction and expression of behavioral sensitization: a critical review of preclinical studies. Psychopharm 151: 99-120.

Wall NR, De La Parra M, Callaway EM, Kreitzer AC (2013). Differential innervation of direct- and indirect-pathway striatal projection neurons. Neuron 79: 347-360.

Wolf ME (1998). The role of excitatory amino acids in behavioral sensitization to psychomotor stimulants. Prog Neurobiol 54: 679-720.

Wettschureck N, Offermanns S (2005). Mammalian G proteins and their cell type specific functions. Physiol Rev 85: 1159-1204. 